\title{
Levels of Sound Pressure in The Neonatal Intensive Care Unit: Professionals Views
}

\author{
Adriana Duarte Rocha ${ }^{1 *}$, Matheus Saggio Silva Azevedo Salvador ${ }^{2}$, Amanda Rocha Chirol $^{3}$, Ana Carolina Carioca \\ da Costa $^{4}$ and Danielle Bonotto Cabral Reis ${ }^{5}$
}

${ }^{1}$ DSc-Reseacher in Public Health-Instituto Nacional de Saúde da Mulher, da Criança e do Adolescente Fernandes Figueira - IFF/Fiocruz, Brazil

${ }^{2}$ Student in Production engineering - IBMEC, Brazil

${ }^{3}$ Student in Production engineering- IBMEC, Brazil

${ }^{4}$ DSc, Statistic-Instituto Nacional de Saúde da Mulher, da Criança e do Adolescente Fernandes Figueira - IFF/Fiocruz, Brazil

${ }^{5}$ MSc-Registered Nurse - Instituto Nacional de Saúde da Mulher, da Criança e do Adolescente Fernandes Figueira - IFF/Fiocruz, Brazil

Submission: July 09, 2019; Published: September 09, 2019

*Corresponding author: Adriana Duarte Rocha, Avenida Rui Barbosa. 716 / bloco C / sala 4, Flamengo - Rio de Janeiro, Brasil

\section{Abstract}

Aim: To evaluate the perception of professionals about noise in a neonatal intensive care unit and to measure sound pressure levels.

Methods: In the first stage of the research the measurement of sound pressure levels (SPL) in the neonatal unit was performed. This measurement was performed during the workday of the professionals. And in the second stage an interview was conducted with the professionals about their perception of the sound pressure levels in the unit.

Results: The analysis showed that the sound pressure levels are above those recommended in all work shift, however the afternoon shift seems to be the noisiest. The intensive care unit was noisier than the conventional intermediate care unit $(\mathrm{p}=0.00)$. When questioned, $72.2 \%$ of respondents perceive that the neonatal unit is an environment with intense noises, with morning being the noisiest period ( $88.9 \%$ of responses). Among the sources of noise, the conversations among professionals were the most cited (50.0\%), followed by alarms from the devices (42.6\%).

Conclusion: The sound pressure levels verified in our neonatal unit were higher than recommended and this was noticed by the professionals who circulate there.

Keywords: Intensive care units; Noise; Monitoring

Abbreviations: NICU: Neonatal Intensive Care Unit; WHO: World Health Organization; SPL: Sound Pressure Levels

\section{Introduction}

The technological advance made it possible to increase the survival rates of newborns treated in Neonatal Intensive Care Units. However, such features as mechanical ventilators, infusion pumps, monitors, incubators and alarms, produce high levels of sound pressure (NPS), making the environment noisy. In addition to these there are the noises produced by the human being, for example, conversations and laughter of employees, not careful handling of furniture, such as dragging chairs, closing cabinets, drawers and garbage covers [1-4].

The World Health Organization (WHO) recommends that, in the hospital environment, the Leq (equivalent pressure level) and the LFMax (maximum sound pressure level) are between 30 and $40 \mathrm{dBA}$ and that, during the night period, reduction of between five and ten percent of the noise level in the unit [5].
Studies show that high levels of sound pressure cause damage to the development of the newborn, such as hypoxia; increased intracranial pressure and blood pressure; apnea; bradycardia; increased oxygen consumption and heart rate, resulting in increased caloric intake [6-9].

Research shows that continuous and excessive noise levels can cause physiological and psychological effects on the health care team, such as high blood pressure, changes in heart rate and muscle tone, headache, hearing loss, confusion, low concentration and irritability , compromising the caregiver's quality of life and may cause Burnout Syndrome and thus compromise patient safety [10-12].

In an attempt to minimize noise levels in neonatal units, some researchers have proposed different strategies, but for to 
be effective, it is necessary to raise awareness of the problem [8,13-15]. Therefore, it is important to know the professionals' perception about noise in a neonatal intensive care unit

\section{Materials and Methods}

This is a cross-sectional study carried out in a tertiary referral hospital of the public network of Rio de Janeiro, RJ, after approval by the Research Ethics Committee of the Institution (approval number 1.827.9 / CAAE 43368315.2.0000.5269) and the application of the Informed Consent Form.
The neonatal unit is divided into intensive care unit, neonatal intermediate care unit and kangaroo unit. The units has approximately 107.79 and $70.81 \mathrm{~m}^{2}$, both of rectangular shape with a height of $2.80 \mathrm{~m}$. The format of both is rectangular. Both units feature high strength flooring, concrete walls without acoustic treatment, glass windows with solar control film that remain closed all the time. The units have automatic glass doors, air-conditioned environments of Split type, a sink located centrally to the two rooms and sinks located near the incubators, not coated with anti-noise material. The group of 2 or 4 incubators are separated by formica shelves (Figure 1).

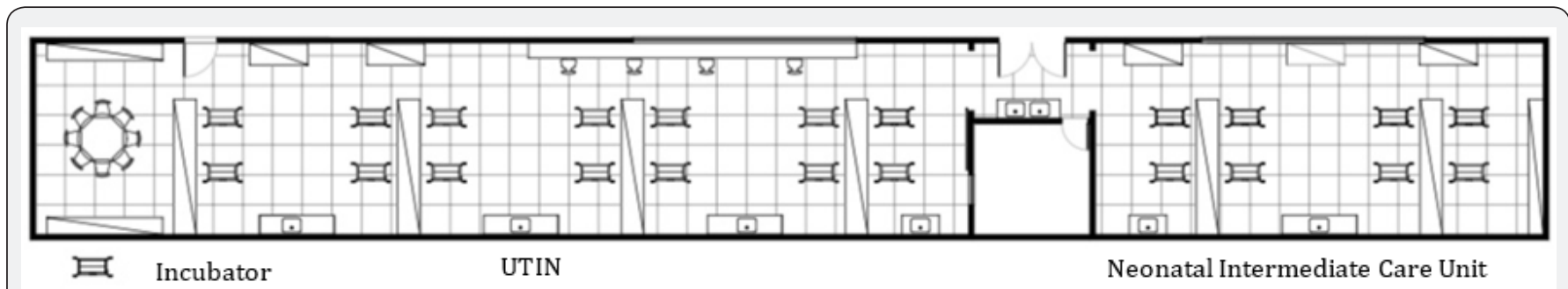

Figure 1: Neonatal Unit.

The Intensive Care Unit has capacity for 12 beds and the Intermediate Care Unit for 8 beds. They are restricted access areas, where only the health staff, cleaning staff, few administrative staff and the parents of newborns circulate. The only exception is on Wednesdays where grandparents are allowed in.

The nursing station is inside the units, where there are telephones and the employees remain when they are not in direct care with the newborns.

The team that operates in the sector is multi-professional, being composed of nurses, nursing technicians, physicians, physiotherapists, speech pathologists, psychologists, occupational therapists and social workers, the nursing team being the most quantitative. The hospital has medical, nursing and multiprofessional residency programs, so there are professionals every year, and training is needed throughout the year.

The research participants were health professionals working in the Neonatal Unit. The inclusion criteria was: a) professional providers of direct care to the newborn;

b) professionals who circulate in the NICU, even if they do not provide direct assistance to the newborn.

The procedures used to develop the research were divided into two stages. In the first stage of the research the measurement of the sound pressure levels (SPL) in the selected sectors was carried out. This measurement was performed during the workday of the professionals. And in the second stage the interview was carried out.

Measurement of sound pressure levels was performed only in the NICU and Intermediate Care Unit. No measurement was performed on the kangaroo unit because it is a unit without technological devices supporting life, therefore, with less possibility of noise.

To measure sound pressure levels the SoundEar ${ }^{\circledR}$ device was used, which is a dosimeter with feedback display capable of collecting 256 measurement values every five minutes. The square root of each measured value is then calculated and divided by 256. The mean value is then stored in the SoundLog ${ }^{\circledR}$ (which is a small box that couples to the SoundEar ${ }^{\circledR}$, which has the capacity to store 8191 measurements, which equals to about 4 weeks of uninterrupted recording.

The frequency range of the device is 20 to $16,000 \mathrm{~Hz}$ (human audible range), with an accuracy of $+/-1 \mathrm{~dB}(\mathrm{~A})$ and a dynamic area of $48 \mathrm{~dB}(\mathrm{~A})$.

The data stored in SoundEar ${ }^{\circledR}$ has been exported to the specific software (SoundLog v.1.3.4). The sound pressure levels were summarized graphically using time series plots.

In the interview stage a questionnaire was made up of closed and open questions.

The database was built in the Epi-Info environment, and all statistical analyzes were performed in the SPSS statistical package, version 13 . The data of the descriptive analysis are presented in the form of distribution (percentages) to characterize the variables.

\section{Results}

The study population was characterized by 54 professionals: 14 physicians, 15 nurses, 14 nursing technicians, 1 physiotherapist, 1 speech pathologist, 1 psychologist, 1 nutritionist, 1 social worker, 1 occupational therapist, 1 cleaning assistant and 4 administrative staff. It is noteworthy that among these professionals there were 
students (residents of medicine and nursing). It is noteworthy that it was not possible to reach all professionals because some workers showed lack of interest in participating in the research.

A total of 13,393 records of sound pressure levels in the neonatal unit were analyzed in the 4-month period. The bed occupancy rate was $100 \%$ for a total of 20 beds. The analysis showed that the sound pressure levels are above those recommended by the WHO in all the shifts, however the afternoon shift seems to be the noisiest. The NICU was noisier than the Intermediate Care Unit ( $\mathrm{p}$ $=0.00$ ) (Tables $1 \& 2)$.

Table 1: Levels of sound pressure in the Neonatal Unit.

\begin{tabular}{|c|c|c|}
\hline \multirow{2}{*}{ Shift } & & dB \\
\hline \multirow{4}{*}{ Dawn } & mean \pm SD & $56,94 \pm 4,8$ \\
\cline { 2 - 3 } & median & 56,50 \\
\cline { 2 - 3 } & Mín - Max & $52-72$ \\
\hline \multirow{4}{*}{ Morning } & mean \pm SD & $59 \pm 5,2$ \\
\cline { 2 - 3 } & median & $50-73$ \\
\cline { 2 - 3 } & Mín - Max & $59,02 \pm 5,1$ \\
\hline \multirow{3}{*}{ Afternoon } & mean \pm SD & 59 \\
\cline { 2 - 3 } & median & $52-74$ \\
\cline { 2 - 3 } & Mín - Max & $58,3 \pm 5,22$ \\
\hline \multirow{2}{*}{ Night } & mean \pm SD & 59 \\
\hline
\end{tabular}

Table 2: Levels of sound pressure according to period and unit.

\begin{tabular}{|c|c|c|c|c|}
\hline Shift & Unit & $\mathbf{N}$ & & dB \\
\hline \multirow{6}{*}{ Dawn } & \multirow{3}{*}{ NICU } & & mean $\pm \mathrm{SD}$ & $58,01 \pm 4,7$ \\
\hline & & 1944 & median & 59 \\
\hline & & & Mín-max & $52-72$ \\
\hline & \multirow{3}{*}{ Intermediate unit } & & mean \pm SD & $55,57 \pm 4,7$ \\
\hline & & 1512 & median & 52 \\
\hline & & & Mín - max & $52-71$ \\
\hline \multirow{6}{*}{ Morning } & \multirow{3}{*}{ NICU } & & mean \pm SD & $60,68 \pm 4,7$ \\
\hline & & 1803 & median & 61 \\
\hline & & & Mín- Max & $50-73$ \\
\hline & \multirow{3}{*}{ Intermediate unit } & & mean \pm SD & $56,64 \pm 5,1$ \\
\hline & & 1400 & median & 56 \\
\hline & & & Mín - Max & 52 \\
\hline \multirow{6}{*}{ Afternoon } & \multirow{3}{*}{$\mathrm{NICU}$} & & mean $\pm \mathrm{SD}$ & $60,53 \pm 4,6$ \\
\hline & & 1834 & median & 61 \\
\hline & & & Mín - Max & $52-72$ \\
\hline & \multirow{3}{*}{ Intermediate unit } & & mean $\pm S D$ & $56,78 \pm 5,1$ \\
\hline & & 1404 & median & 56 \\
\hline & & & Mín - Max & $52-74$ \\
\hline \multirow{7}{*}{ Night } & \multirow{4}{*}{ NICU } & & mean $\pm \mathrm{DP}$ & $60,13 \pm 4,7$ \\
\hline & & 1944 & median & 60 \\
\hline & & & Mínimo & 52 \\
\hline & & & Maximo & 73 \\
\hline & \multirow{3}{*}{ Intermediate unit } & & mean $\pm \mathrm{DP}$ & $56,04 \pm 4,9$ \\
\hline & & 1402 & median & 52 \\
\hline & & & Mín - Max & $52-75$ \\
\hline
\end{tabular}


A total of 54 volunteers, 48 women and 6 men, with a mean age of $32 \pm 6.8$ years, including medical staff $(25.9 \%)$, nursing staff (51.8\%), multi-professional team (11.1\% \%), administrative staff (7.4\%) and cleaning staff (1.8\%) participated the research. These professionals stay in the neonatal unit for a median of time of 12 hours (min: 1 - max: 24).

$72.2 \%$ of respondents perceived that the neonatal unit is an environment with intense noises, with the morning being the noisiest period (88.9\% of responses). The perception of these professionals about the noise level is shown in Table 3.

Table 3: Perception about the noise level.

\begin{tabular}{|c|c|c|}
\hline Professional Category & Loud Noise & Moderate Noise \\
\hline Medical Team & $71,4 \%$ & $28,6 \%$ \\
\hline Nursing Team & $78,5 \%$ & $21,5 \%$ \\
\hline Multiprofessional Team & $100 \%$ & $0,0 \%$ \\
\hline Administrative Team & $25,0 \%$ & $75,0 \%$ \\
\hline Cleaning staff & $0,0 \%$ & $100 \%$ \\
\hline
\end{tabular}

According to the interviewees, the existing noise in the neonatal unit is a result of the sum of noise generated by equipment with those generated by professionals ( $70.4 \%$ of the answers).

The conversations of professionals were the sources of noise most cited (50.0\%), followed by alarms of the devices (42.6\%). Other sources were cited: bathing and aspiration of patients, shaking of newborns, handling of equipment, many people hanging around, inefficient equipment, newborn admission, telephone ringing, and unit cleaning.

Among the interviewees, $57.4 \%$ believe that their behavior in the neonatal unit generates noise, while $31.4 \%$ say they believe their behavior is not noise-generating. $11.1 \%$ of them don't know if noise is produced. It is important to note that among the professionals who answered that their behavior can generate noise, $93.5 \%$ believe that the most harmful is the conversation in the unit.

When questioned, $94.4 \%$ of the interviewees said that it would be possible to reduce the noise level in the neonatal unit. Only $5.6 \%$ of respondents do not believe in noise reduction. The interviewees point out as the main tool for noise reduction is the management and training of the team. Concerning the effects of noise for the newborn, the interviewees indicated physiological and behavioral manifestations. The physiological effects pointed out by the professionals were: tachycardia and saturation fall. Among the behavioral manifestations resulting from noise, stress, irritation, agitation, annoyance, nervousness and anxiety were highlighted. Only one subject reported no perceived effect on neonates.

Professionals reported that unit noise causes stress $(74 \%$ of responses), irritability, hearing changes, difficulty concentrating, fatigue and anxiety

\section{Discussion}

Published studies show that Neonatal Intensive Care Units have high levels of sound pressure, due to the characteristic itself, that is, due to the existing technological devices. Such studies indicate that the human element is also a source of noise [1-4].

Nevertheless, regulatory agencies recommend the maximum sound pressure levels for these environments $[5,16,17]$, which are often exceeded, according to studies using decibelimeters and dosimeters [3,18-20].

In the present study, it was also observed levels of sound pressure above the recommended level, especially in the intensive care unit, which was already expected, since in this unit are the most serious newborns who need more equipment, moreover , has the highest number of beds and, consequently, the highest number of professionals in circulation.

It is interesting to note that $72.2 \%$ of respondents are aware that the neonatal unit is an environment with intense noises, with the morning being the noisiest period (88.9\% of the responses) and that the conversations between the professionals are one of the main sources of noise ( $50 \%$ of responses).

It is noteworthy that although the professionals pointed to the morning shift as the noisiest, records showed that the noisiest shift was that of the afternoon. Such perception can be because in the morning shift there are more people circulating and it is the time where the baths take place, gastric tube changes, baby weighing and medical round. However, it was observed that the shift where the conversations between the professionals happened most of the time was the afternoon.

Although professionals have a very realistic perception of noise and its sources, as well as the impact of noise on the health of newborns and the professionals themselves, their behavior is not modified. Among the interviewees, $94.4 \%$ believe that it is possible to reduce the noise level in the neonatal unit and point out the management and training of the team as the main tool for noise reduction. A review on noise in the neonatal unit, Casavant et al [21] recommends the implementation of interventions with close attention to initial and continuing training of staff with involvement and appropriation of the topic.

\section{Conclusion}

The sound pressure levels verified in the neonatal unit studied were higher than recommended and this was noticed by the professionals that circulate there.

\section{References}

1. Rodarte MDO, Scochi CGS, Leite AM, Fujinaga CI, Zamberlan NB, et al. (2005) 0 ruído gerado durante a manipulação das incubadoras: Implicação para o cuidado de enfermagem. Rev Latino-am Enfermagem 13(1): 79-86.

2. Aurélio FS, Tochetto TM (2010) Ruído em uma unidade de terapia intensiva neonatal: mensuração e percepção de profissionais e pais. Rev Paul Pediatr 28(2): 162-169. 
3. Cardoso MVLM, Chaves EMC, Bezerra MGA (2010) Ruidos e barulhos na unidade neonatal. Rev Bras Enferm 63(4): 561-566.

4. Peixoto PV, Balbino FS, Chimirri V, Pinheiro EM, Kakehashi TY (2011) Ruído no interior das incubadoras em unidade de terapia intensiva neonatal. Acta Paul Enferm 24 (3): 359-364.

5. World Health Organization, 1999. Guidelines for Community Noise.

6. Ranganna R, Bustani P (2011) Reducing noise on the neonatal unit. Infant 7(1): 25-28.

7. Trapanotto M, Benini F, Farina M, Gobber D, Magnavita V, et al. (2004) Behavioural and physiological reactivity to noise in the newborn. J. Paediatr Child Health 40(5-6): 275-281.

8. Philbin MK, Gray L (2002) Changing leves of quiet in an intensive care nursery. Journal of Perinatology 22: 455-460.

9. Graven SN (2000) Sound and the developing infant in the NICU: Conclusions and recommendations for care. J Perinatol 20: S88-S93.

10. Parente S, Loureiro R (2001) Quality improvement in ICU . ICU noise pollution. Eur J Anaesthesiol v. 18 (Suppl 21): 5.

11. Brasil. Ministério da Saúde. Secretaria de Atenção à Saúde. Departamento de Ações Programáticas Estratégicas. Perda auditiva induzida por ruído (Pair) / Ministério da Saúde, Secretaria de Atenção à Saúde, Departamento de Ações Programáticas Estratégicas. - Brasília : Editora do Ministério da Saúde, 2006. p. 40.

12. Daniele D, Pinheiro EM, Kakehashi TY, Balieiro MMFG (2012) Conhecimento e percepção dos profissionais a respeito do ruído na unidade neonatal. Rev Esc Enferm USP 46(5): 1041-1048.

13. Zamberlan-Amorim NE, Fujinaga CI, Hass VJ, Fonseca LMM, Fortuna CM, et al. (2012) Impacto de um programa participativo de redução do ruído em unidade neonatal. Rev. Latino-Am. Enfermagem 20(1):109116.

14. Swathi S, Ramesh A, Nagapoornima M, Fernandes LM, Jisina C, et al. (2014) Sustaining a culture of silence" in the neonatal intensive care unit during nonemergency situations: A grounded theory on ensuring adherence to behavioral modification to reduce noise levels. Int J Qual Stud Health Well-being 9: 22523.

15. Laubach V, Wilhelm P, Carter K (2014) Shh. I'm growing: noise in the NICU. Nurs Clin N Am 2014; 49: 329-344.

16. American Academy of Pediatrics, Commitee on Environmental Health (1997) Noise: a hazard for the fetus and newborn. Pediatrics 100(4): 724-727.

17. Associação Brasileira de Normas Técnicas. NBR 10151:1999. Acústica - Avaliação do ruído em áreas habitadas, visando o conforto da comunidade - procedimento. Rio de Janeiro: ABNT;2000.

18. Lahav A (2014) Questionable sound exposure outside of the womb: frequency analysis of environmental noise in the neonatal intensive care unit. Acta Paediatr 104(1): e14-19.

19. Valizadeh S, Hosseini MB, Alavi N, Asadollahi M, Kashefimehr S (2013) Assessment of Sound Levels in a Neonatal Intensive Care Unit in Tabriz, Iran. J Caring Sci 2(1): 19-26.

20. Kakehashi TY, Pinheiro EM, Pizzarro GP, Guilherme A (2007) Nível de ruído em unidade de terapia intensive neonatal. Acta Paul Enferm 20(4): 404-409.

21. Casvant SG, Bernier K, Andrews S, Bougoin A (2017) Noise in the Neonatal Intensive Care Unit: What does the evidence tell us? Advances in Neonatal Care 17(4): 265-273.

\section{Your next submission with Juniper Publishers will reach you the below assets}

- Quality Editorial service

- Swift Peer Review

- Reprints availability

- E-prints Service

- Manuscript Podcast for convenient understanding

- Global attainment for your research

- Manuscript accessibility in different formats

( Pdf, E-pub, Full Text, Audio)

- Unceasing customer service

Track the below URL for one-step submission https://juniperpublishers.com/online-submission.php 